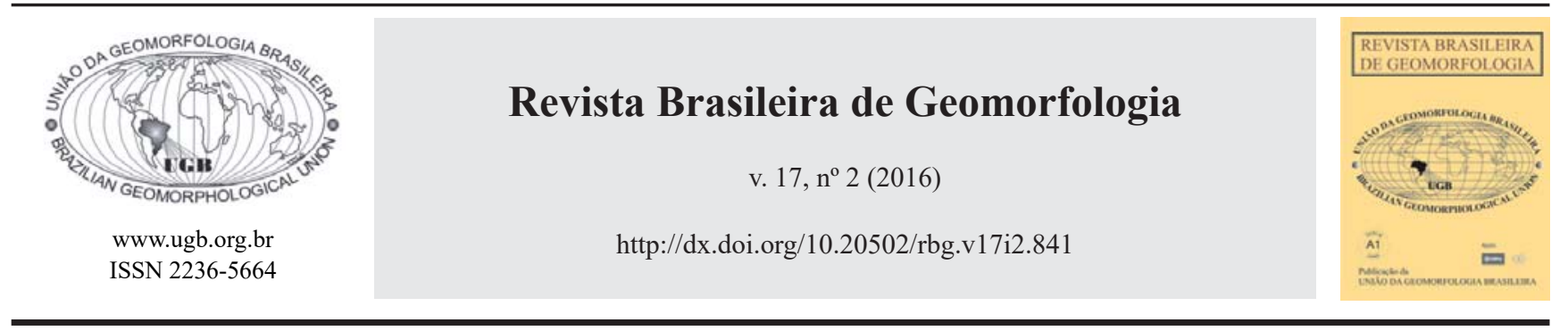

\title{
ASPECTOS MORFODINÂMICOS EM PRAIAS DE ENSEADA: ESTUDO DE CASO EM ARMAÇÃO DOS BÚZIOS, RJ
}

\section{MORPHODYNAMICS OF EMBAYED BEACHES: CASE STUDY IN ARMAÇÃO DOS BÚZIOS, RJ, BRAZIL}

\author{
Eduardo Bulhões \\ Departamento de Geografia, Universidade Federal Fluminense \\ Rua José do Patrocínio, 71, Campos dos Goytacazes, Rio de Janeiro, CEP 28010-385, Brasil
}

Email:eduardobulhoes@id.uff.br

Guilherme Borges Fernandez

Departamento de Geografia, Universidade Federal Fluminense

Av. General Milton Tavares de Souza, s/n, Niterói, Rio de Janeiro, CEP 24210-346, Brasil

Email: guilhermefernandez@id.uff.br

\section{Informações sobre o Artigo}

Recebido (Received):

04/09/2015

Aceito (Accepted):

03/04/2016

Palavras-chave:

Praias de Enseada;

Morfodinâmica de Praias;

Armação dos Búzios.

Keywords:

Embayed Beaches; Beach Morphodynamics; Armação dos Buzios.

\section{Resumo:}

O segmento costeiro selecionado para o estudo sobre dinâmica de praias de enseada foi o cabo Búzios por se tratar de uma protuberância natural da linha de costa composta por praias de variados tamanhos e formas, orientadas e expostas às ondulações dos quadrantes nordeste ao sudoeste. A transformação das ondas em águas rasas expõe ou protege determinados segmentos das enseadas e esta exposição relativa e suas sucessões controlam os processos morfológicos, morfodinâmicos e morfossedimentares atuais, estando aí inclusos a distribuição e o transporte de sedimentos superficiais, as feições da praia e da antepraia e as respostas morfológicas dos perfis praiais frente a alternância de períodos de tempestade e tempo bom. O objetivo geral é diagnosticar os processos governantes da dinâmica costeira em praias de enseada. Os passos metodológicos adotados visaram: (a) determinar os principais padrões de circulação e transporte de sedimentos; (b) determinar as características morfodinâmicas; (c) entender à relação entre a exposição relativa das praias ao ataque das ondas; e (d) prognosticar os efeitos morfológicos que podem ser esperados nestes ambientes frente aos processos governantes. Os principais resultados indicam que as inconsistências verificadas entre o padrão de ondas e o registro de transporte de sedimentos podem ser atribuídas a uma condição de tri modalidade da circulação promovida por ondas, que são: (a) tempo bom com ventos soprando entre NNE (nor-nordeste) e ESE (leste-sudeste); (b) tempo bom com marulhos de sul ou de sudeste; (c) tempestade com ondas que variam entre su-sudeste $\left(157^{\circ}\right)$ até sudoeste $\left(225^{\circ}\right)$. As características morfodinâmicas dos perfis monitorados permitem classifica-los em ambientes de baixa energia e de alta energia que podem ser: (a) refletivos de baixa energia; (b) intermediários de baixa energia, sujeitos a eventos episódicos de tempestade; (c) dissipativos de baixa energia; e (d) intermediários de alta 
energia. As respostas destes ambientes quanto a um possível aumento na magnitude dos eventos extremos podem ser o desaparecimento sazonal dos ambientes intermediários de baixa energia e um recuo erosivo dos ambientes intermediários de alta energia. Estas respostas ocorrem em função direta do estoque de sedimentos. Por fim verificou-se que os limites ativos sobre a influência das ondas dentro das enseadas podem ser determinados entre 1 e $6 \mathrm{~m}$ de profundidade em todas as áreas tidas como de baixa energia no cabo Búzios; já nas áreas sujeitas à alta energia de ondas este limite ocorre em profundidades superiores a $20 \mathrm{~m}$.

\begin{abstract}
:
Cape Buzios has been the coastal segment selected because it is a lump of natural coastline that support several beaches of various sizes and shapes, oriented and exposed to swell and wind seas from northeast to southwest. In this sense, the topics discussed are the participation of the geometric orientation of the beach-shoreface system and exposure to different conditions of wave climate in defining the boundaries of the submerged beaches and also the use of variables that contribute as indicators of coastline stability. The hypothesis tested is that the transformation of ocean waves that are propagated to shallow waters, protect and expose certain segments of embayed beaches. These wave alternations control the morphological processes and the morphodynamics of embayed beaches, being there included the distribution and transport of sediments, the modifications of features of the beach and the shoreface and the morphological responses of the beach profiles front of storm events and subsequent recovery of these morphological features. To this end, methodological steps adopted aimed to: (a) determine the main circulation patterns and sediment transport; (b) determine the morphodynamic characteristics; (c) understand the relationship between exposures to the wave attack and (d) predict the morphological effects that can be expected in these embayed beaches. The main results indicates that the inconsistencies between the wave pattern and the record of sediment transport (assessed from the distribution of their statistical parameters such as mean, standard deviation and skewness) can be attributed to a condition of the circulation promoted by multimodal waves, which are: (a) fair weather with winds blowing from NNE (north northeast) and ESE (east southeast), (b) fair weather with swell from the south or southeast, (c) storm weather with waves ranging from south southeast $\left(157^{\circ}\right)$ to southwest $\left(225^{\circ}\right)$. Additionally, the morphodynamic characteristics of beach profiles monitored together with the morphological and sedimentological attributes are controlled primarily by the effect of waves and their relative exposure on beaches. Overall the 12 monitored profiles are ranked among environments of low energy and high energy that can be: (a) low-energy reflective beaches, (b) low-energy intermediate beaches subjected to episodic storm events (c) low-energy dissipative beaches and (d) high-energy intermediate beaches. In this context, the response of these environments on a possible increase in the magnitude of extreme events are: seasonal disappearance of intermediate and low energy beaches and erosive retreat of high-energy intermediate beaches, the latter being a direct function of the stock of sediments. Finally it was found that the active limits the influence of the waves can be measured around the depth of between 1 and $6 \mathrm{~m}$ in all areas of low energy taken and, in areas subjected to high energy waves, this limit can be transferred to depths exceeding $20 \mathrm{~m}$.
\end{abstract}

\section{Introdução}

Praias de enseada são feições geomorfológicas encaixadas entre pontas e promontórios rochosos ou margens artificiais pré-existentes que assumem curvatura definida em função da disponibilidade de sedimentos e do padrão de circulação hidrodinâmica induzido por ondas. Leatherman (1988) tratou estes ambientes como barreiras arenosas encaixadas (bayhead barriers), que através dos movimentos de transgressão e regressão marinha afogaram vales fluviais, preenchendo-os com sedimentos. Davis Jr. (1985) considerou que boa parte dos sedimentos são localmente disponibilizados e refletem a característica geológica local. Jackson et al. (2005) consideraram que os processos hidrodinâmicos que influenciam a dinâmica destas praias são controlados pela disposição da estrutura geológica antecedente, como a presença de costões rochosos, ilhas, lajes submersas, etc. Short (1999) e Klein (2004) acrescentaram que apesar da estrutura rochosa ser totalmente independente dos processos de formação das praias, exerce papel fundamental no formato em planta, no transporte de sedimentos e nos aspectos morfodinâmicos das praias que abrigam. 
Em praias de enseada, a curvatura assumida no aspecto em planta pode ser de variados tipos, mas normalmente ocorre associada ao padrão de refração e difração que as ondas sofrem de acordo com a disposição dos promontórios rochosos (DAVIES, 1958 e 1972), estruturas artificiais, presença de ilhas ou lajes rochosas. Alguns modelos numéricos (empíricos) confirmam isto, como exemplo, Logarithmic Spiral Shape (KRUMBEIN, 1944; YASSO, 1965), Parabolic Bay Shape (HSU e EVANS, 1989; SILVESTER e HSU, 1997) e o Hyperbolic-Tangent Shape (MORENO e KRAUS, 1999; MARTINO et al., 2003).

Recentemente o papel do controle geológico em praias tem sido considerado em estudos de curto termo (THIELER et al. 1995; McNINCH, 2004; JACKSON et al. 2005) e longo termo (COOPER e PILKEY, 2004) caracterizado normalmente através de três pontos: $(a)$ controle que inibe a praia de se movimentar lateralmente ou mesmo verticalmente; (b) volume deficitário de sedimentos; e (c) modificações hidrodinâmicas induzidas pela presença de obstáculos como ilhas, lajes e promontórios rochosos.

Mahiques et al. (1998) consideraram que a interação entre a direção de incidência das ondas com a extensão e orientação das aberturas das enseadas, além da presença de ilhas ou lajes rochosas na plataforma continental interna, levam a ocorrência de significativas variações na dinâmica das enseadas. As diferenças nos níveis de energia entre as enseadas estão, assim, fortemente associadas à direção de incidência das ondas e à orientação de suas aberturas. Ainda segundo os autores, os dados de distribuição de sedimentos de fundo revelam a possibilidade de se estabelecer o gradiente de energia dos agentes hidrodinâmicos que agem sobre o fundo de determinada enseada.

Loureiro et al. (2009) mostraram que a maior diferença nos impactos morfológicos sofrida por praias de enseada durante eventos de tempestade está associada à posição relativa destas às entradas de ondas de maior energia. Logo, a orientação das praias de enseada influi significativamente no impacto sofrido e no processo erosivo desencadeado.

O efeito imobilizador e de efetiva proteção oferecido por costões rochosos tem influência significativa no formato em planta, no transporte de sedimentos e na morfodinâmica de praias de enseada. O comportamento morfológico nestes ambientes é principalmente determinado pelo formato em planta e pelo índice de endentação (SILVESTER, 1960), comprimento da praia, presença de correntes de retorno e barras submersas, tipo morfodinâmico, distribuição longitudinal de sedimentos e declividade do sistema praia antepraia (SHORT, 1999; KLEIN, 2004; LOUREIRO et al., 2009). Além disto, o controle estrutural potencializa ou limita determinados processos hidrodinâmicos, como o transporte de sedimentos e a distribuição de energia nas enseadas (SHORT, 1999; JACKSON et al., 2005). As respostas destes tipos de praia à forçantes externos são afetadas por efeitos de borda, incluindo refração, difração, reflexão, atenuação e o comportamento da circulação induzida por ondas.

\section{Objetivos}

O objetivo deste trabalho é determinar os principais padrões de circulação, transporte de sedimentos e as características morfodinâmicas das praias no cabo Búzios. Busca-se apresentar a relação entre exposição relativa ao ataque das ondas e as transformações morfológicas frente aos eventos de maior energia.

\section{Área de estudo}

Foram selecionadas, como área de estudo, as enseadas do cabo Búzios (Figura 1), no município de Armação dos Búzios, Rio de Janeiro, onde a formação de enseadas voltadas para direções que variam entre o norte e o sul, com dimensões e formas distintas, permitiram a avaliação de situações que auxiliaram a atingir os objetivos traçados.

Esta área está fisiograficamente localizada no flanco sul do macro-compartimento da bacia de Campos (MUEHE, 1998b). Ao norte do cabo Búzios tem-se uma planície costeira associada à sedimentação dos rios Una, São João e das Ostras, marcados por feixes paralelos de cristas de praias, afloramentos terciários do Grupo Barreiras e afloramentos cristalinos (AMADOR, 1980; MARTIN e SUGUIO, 1989; FERNANDEZ, 1998). Ao sul existem três grandes arcos praiais até o cabo Frio, ancorados em promontórios rochosos cristalinos e ainda outros arcos praiais menores são encontrados, com orientações diversas (SAAVEDRA, 1994) além de ilhas dispostas com tendência paralela à linha de costa. A disposição das linhas batimétricas também pode ser compartimentada observando-se os padrões ao norte e 


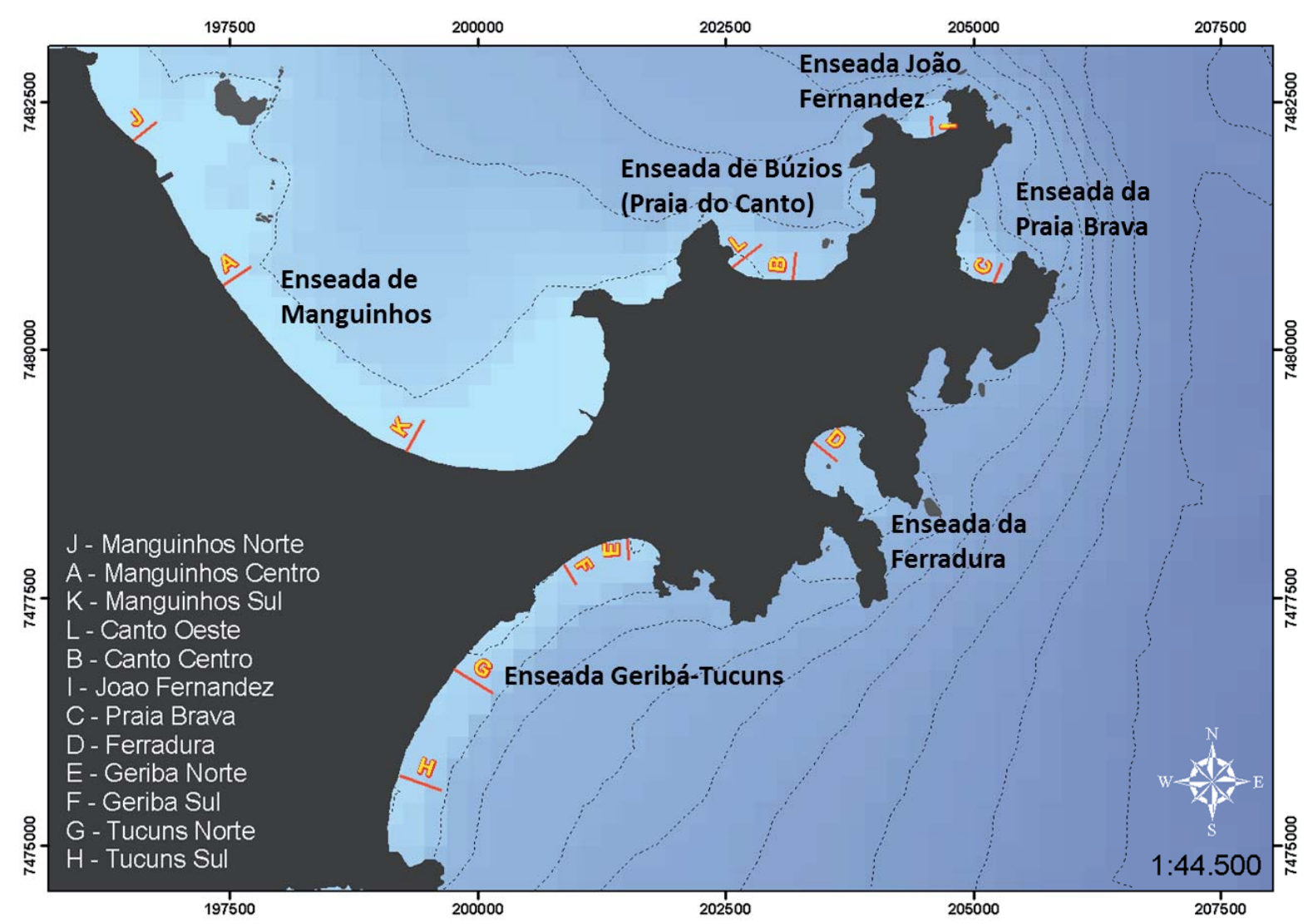

Figura 1 - Localização da área de estudo, toponímia das enseadas e distribuição dos perfis de monitoramento.

ao sul. Ao norte, há um distanciamento que indica um relevo submarino aplainado e de transição mais suave ao longo da plataforma continental interna. Ao sul as isolinhas acompanham o formato das enseadas até as proximidades dos $20 \mathrm{~m}$.

Em termos geológicos o cabo Búzios está inserido no segmento oriental e oceânico do Rift Continental do Sudeste Brasileiro de acordo com a denominação de Riccomini (1989) cuja principal feição é o Gráben de Barra de São João que se estende ao longo da zona submarina entre o cabo Búzios e Macaé. Considerase ainda a Falha do Pai Vitório (borda norte do cabo Búzios) como continuidade deste limite sul do gráben supracitado. Mohriak et al. (1990) identificaram o Gráben de Barra de São João e constataram a sedimentação associada ao Grupo Barreiras. Análises geofísicas para o litoral sudeste brasileiro e interpretadas por Zalan e Oliveira (2005) mostram o cabo Búzios integrado ao Domínio Tectônico de Cabo Frio e à unidade litotectônica supracrustal composta por rochas metassedimentares e metavulcânicas. Em termos estruturais Heilbron et al., (1982) estabeleceram a estratigrafia local, incluindo o
Complexo Região dos Lagos e Schmitt (2001) apresentou a Orogenia Búzios como um evento colisional bem definido no Cambriano e no Ordoviciano (530 a 490 $\mathrm{Ma}$ ), tido como o evento tectono-metamórfico mais recente registrado nas faixas móveis brasilianas do Brasil.

\section{Metodologia}

A estratégia metodológica para o entendimento morfodinâmico das enseadas do cabo Búzios partiu da definição de uma base cartográfica comum - compilação dos dados das cartas náuticas CN1504, CN1505 e das folhas de bordo FB1505-001 e FB1500-001 - e da definição de 12 pontos de monitoramento (indicados na Figura 1) representativos de sete enseadas, a saber: três pontos na enseada de Manguinhos (J, A e K); dois pontos na enseada de Búzios/praia do Canto (L e B); um ponto na enseada de João Fernandez (I); um ponto na enseada da praia Brava (C); um ponto na enseada da Ferradura (D); e quatro pontos na enseada de GeribáTucuns, dois deles na praia de Geribá (E e F) e dois na praia de Tucuns ( $\mathrm{G}$ e $\mathrm{H})$. 
No total foram levantados 231 perfis de praia, utilizando métodos padrão de nivelamento topográfico, entre os anos de 2007 e 2014, e a cada levantamento foram calculados parâmetros para caracterização morfodinâmica utilizando para tal uma suíte de informações coletadas in situ, calculadas ou estimadas a partir de modelos empíricos (Tabela 1), sendo estes comuns em estudos de dinâmica costeira.

Os parâmetros calculados para a apresentação neste artigo foram: o Surf-Scaling Parameter (CARRIER e GREENSPAN, 1958; GUZA e BOWEN, 1975; GUZA e INMAN, 1975) que avalia o grau de refletividade ou de dissipação de energia de ondas ao longo da zona de surfe; o parâmetro Delta, proposto por Muehe (1998a), que entende a zona de surfe como um filtro cuja função é modificar a onda incidente através da morfologia do fundo e das condições no momento da observação e ainda tem limites definidos para caracterizar os estágios morfodinâmicos propostos por Wright e Short (1984); o Surf Similarity Parameter (BATJES, 1974) que utiliza as características das ondas e da declividade do perfil ativo para determinar o tipo de arrebentação entre progressiva, mergulhante e ascendente/colapsante; e o parâmetro de embaiamento - Embayment Scaling
Parameter - proposto por Martens et al. (1999) que consideram o comprimento da linha de praia, o comprimento da corda da enseada, declividade da zona de surfe e altura de onda na arrebentação, presumindo de acordo com Short (1999) três padrões de circulação sendo eles o celular, em que há o predomínio da circulação longitudinal e processos típicos de ambientes de enseada confinada, o transicional no qual a influência dos promontórios rochosos ou estruturas artificiais é restrita às extremidades e o normal em que a circulação hidrodinâmica é similar às praias expostas, sem influência de promontórios rochosos ou estruturas artificiais. Adicionalmente foi calculado o perfil de equilíbrio de acordo com o proposto por Dean (1977) segundo base teórica de Brunn (1954) e estimada a profundidade de fechamento para cada perfil de acordo com os modelos de Hallemeier (1981) e estimativas desta profundidade para o período retorno de 100 anos, de acordo com o proposto por Nicholls et al. (1995).

Ainda utilizando os levantamentos morfológicos foi calculada a variação volumétrica de cada levantamento visando evidenciar a flutuação do estoque sedimentar emerso que compõe a morfologia dos perfis ao longo do tempo de monitoramento.

Tabela 1: Parâmetros calculados para caracterização morfodinâmica.

\begin{tabular}{|c|c|}
\hline Parâmetros Observacionais Estimados & Parâmetros Calculados em Gabinete \\
\hline Altura de Ondas na Arrebentação $(\mathrm{Hb})$ & Comprimento de Ondas (L) \\
\hline Parametros Medidos & Celeridade de Ondas ( C ) \\
\hline Período de Ondas (T) & Energia de Ondas (E) \\
\hline $\begin{array}{l}\text { Caracteristicas Angulares das Ondas (sen, } \\
\text { cos e tan) }\end{array}$ & Energia no Embaiamento \\
\hline Tempo do Espraiamento (Tup) & Índice de Arrebentação $(\lambda)$ \\
\hline Tempo do Espraiamento/Refluxo (Tswash) & Velocidade Orbital Horizontal (u) \\
\hline $\begin{array}{l}\text { Cota do Alcance Máximo das Ondas (AM } \\
\text { Cota) }\end{array}$ & Velocidade de Atrito (u*) \\
\hline $\begin{array}{l}\text { Cota do Recuo Máximo das Ondas (RM } \\
\text { Cota) }\end{array}$ & Tensão no Fundo $(\tau b)$ \\
\hline $\begin{array}{l}\text { Características Angulares da Face da Praia } \\
\text { (sen, cos e tan) }\end{array}$ & Parametro de Shields (S) \\
\hline $\begin{array}{l}\text { Características Angulares do Perfil Ativo } \\
\text { (sen, cos e tan) }\end{array}$ & Numero de Reynolds ( R ) \\
\hline Parâmetros Modelados & Velocidade de Grupo (Cn) \\
\hline Altura de Ondas ao Largo (Ho) & Volume de Areia Transportada/Dia (Qs) \\
\hline Direção de Ondas ao Largo (MWD) & Velocidade da Corrente Longitudinal(VI) \\
\hline Altura Significativa de Ondas (Hs) & Surf Scaling Parameter \\
\hline Velocidade do Vento a 10m (U10) & Surf Similarity Parameter \\
\hline Direção do Vento & Embayment Scale Parameter \\
\hline \multirow[t]{3}{*}{ Perfil de Equilibrio } & Delta \\
\hline & Profundidade de Fechamento \\
\hline & Altura Significativa de Ondas Extrema (Hs ext) \\
\hline
\end{tabular}

Fonte: Laboratório de Geografia Física da Universidade Federal Fluminense. 
Adicionalmente foram realizadas coletas e análise granulométrica (incluindo queima de carbonatos) por peneiramento a seco de 265 amostras de sedimentos no sistema praia-antepraia e plataforma continental interna em ordem de identificar padrões de erosão, transporte - utilizando aqui o modelo GSTA (GAO e COLLINS (1994) e GAO (1996)) - e deposição de sedimentos.
Por fim, foram realizadas simulações de distribuição de energia de ondas em águas rasas para as principais entradas de ondas. Para tal, foram identificadas 69 tempestades entre abril de 2003 e dezembro de 2013 (Tabela II) para a posição geográfica $\left(24^{\circ} 0^{\prime} \mathrm{S}, 41^{\circ} 40^{\prime} \mathrm{W}\right)$ que atendiam à padronização de ondas maiores que $3 \mathrm{~m}$ ocorrendo por um período mínimo de 12 horas (BULHÕES et al. 2014).

Tabela 2: Características dos eventos de ondas de tempestade para o litoral Centro-norte do Rio de Janeiro.

\begin{tabular}{|c|c|c|c|c|c|}
\hline Ano & $\begin{array}{c}\text { Total de } \\
\text { Eventos de } \\
\text { Tempestade }\end{array}$ & $\begin{array}{l}\text { Duração Média } \\
\text { (h) }\end{array}$ & $\begin{array}{l}\text { Altura Média } \\
\text { das Ondas } \\
\text { (m) }\end{array}$ & $\begin{array}{c}\text { Direçäo } \\
\text { Média de } \\
\text { entrada das } \\
\text { ondas ( }{ }^{\circ} \mathrm{N} \text { ) }\end{array}$ & $\begin{array}{c}\text { Altura } \\
\text { Máxima de } \\
\text { Ondas (m) }\end{array}$ \\
\hline 2003 & 6 & 30 & 3,07 & 191,82 & 3,60 \\
\hline 2004 & 11 & 31 & 3,06 & 178,82 & 3,40 \\
\hline 2005 & 3 & 54 & 3,05 & 164,70 & 3,40 \\
\hline 2006 & 10 & 43 & 3,31 & 177,81 & 4,10 \\
\hline 2007 & 9 & 39 & 3,36 & 191,63 & 4,50 \\
\hline 2008 & 9 & 32 & 3,10 & 162,53 & 3,90 \\
\hline 2009 & 9 & 32 & 3,17 & 180,00 & 3,70 \\
\hline 2010 & 3 & 48 & 3,51 & 169,73 & 4,70 \\
\hline 2011 & 5 & 37 & 3,21 & 186,27 & 3,50 \\
\hline 2012 & 0 & - & - & - & - \\
\hline 2013 & 4 & 32 & 3,33 & 188,23 & 4,30 \\
\hline total & 69 & 38 & 3,22 & 179,15 & 3,55 \\
\hline Mês & $\begin{array}{c}\text { Total de } \\
\text { Eventos de } \\
\text { Tempestade }\end{array}$ & Mês & $\begin{array}{c}\text { Total de } \\
\text { Eventos de } \\
\text { Tempestade }\end{array}$ & Mês & $\begin{array}{c}\text { Total de } \\
\text { Eventos de } \\
\text { Tempestade }\end{array}$ \\
\hline Jan & 1 & Mai & 11 & Set & 9 \\
\hline Fev & 1 & Jun & 9 & Out & 3 \\
\hline Mar & 1 & Jul & 7 & Nov & 7 \\
\hline Abr & 7 & Ago & 11 & Dez & 2 \\
\hline
\end{tabular}

Fonte: Modelo WaveWatch III em Bulhões et al. (2014).

A partir desta identificação das tempestades, foram selecionados cinco eventos sendo estes os mais significativos para cada direção de incidência, a saber:

- Julho, 2005: ondas de sul, sudeste e leste-sudeste. Altura Máxima de Ondas 3,4m e duração de 102 horas.

- Junho, 2007: Ondas de su-sudoeste. Altura Máxima de Ondas 3,7m e duração de 39 horas.

- Novembro, 2008: Ondas de leste-sudeste. Altura Máxima de Ondas 3,2m e duração de 75 horas.

- Abril, 2010: Ondas de sul, su-sudoeste e su-sudeste. Altura Máxima de Ondas 4,7m e duração de 75 horas.
Adicionalmente foi usado o evento de dezembro de 2006 para simular as condições ditas de bom tempo (PINHO, 2003) com altura máxima de 2,2m e ondas incidentes de nordeste e leste ocorrendo por 13 dias.

\section{Resultados e Discussão}

As características sedimentares do sistema praia -antepraia e plataforma continental interna apontam heterogeneidade do diâmetro médio dos sedimentos indicando a presença de agentes erosivos e deposicionais distintos, tanto na borda norte quanto na borda sul do 
cabo Búzios. Esta informação sustenta uma hipótese de bi ou tri modalidade hidrodinâmica ao qual esta porção do litoral está submetida.

Quando comparados os valores de diâmetro médio e desvio padrão do universo de amostras (Figura 2) os resultados apontam nítida separação entre as areias médias e finas que são moderadamente selecionadas, das amostras de siltes que tendem a ser naturalmente mal e muito mal selecionadas, conforme já descrito por Inman (1949). Existe, assim, esta modulação entre depositários de siltes e depositário de areias.

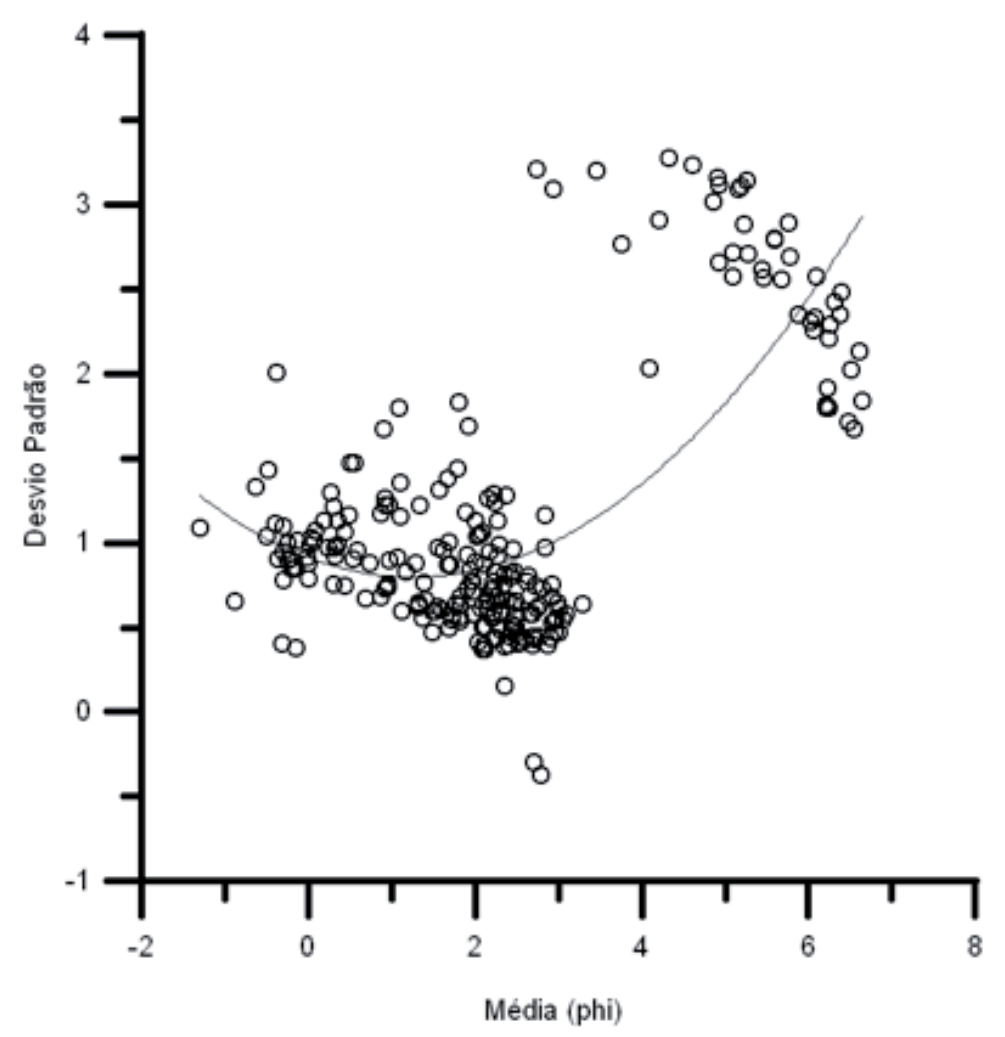

Figura 2 - Correlação entre diâmetro médio e o desvio padrão das amostras.

A mancha amarela (e duas tonalidades abaixo) ao norte do mapa da Figura 3 representa a extensão próxima à costa de um depósito superficial de siltes associados à sedimentação fluvial, conforme já identificado por Saavedra e Muehe (1993) e Fernandez e Muehe (1995), onde a sedimentação dos rios Macaé e Paraíba do Sul, ao norte, parecem ser a fonte. McManus (1975) descreveu como neotérica (moderna) a sedimentação superficial ajustada às condições hidrodinâmicas atuais. Ao sul do cabo Búzios, esta influência aparece também na forma de manchas, próxima à linha batimétrica de $20 \mathrm{~m}$, sobreposta aos sedimentos predominantemente arenosos, o que indica ser o mesmo tipo de sedimentação.

Ao se aproximar da linha de costa as amostras tendem a apresentar predominantemente diâmetros de areia média e fina em quase todas as enseadas (excetuando as posições de Tucuns aonde as areias são médias e grossas), resultado da não deposição da fração silte em áreas de hidrodinâmica mais turbulenta, onde então prevaleceriam sedimentos palimpsestos e ou reliquiares, que seriam a porção submersa da barreira arenosa que têm sido erodida e transportada em direção à costa. Outro destaque é para os sedimentos classificados como areias grossas, muito grossas e até cascalhos nas proximidades de costões rochosos, ilhas, ou mesmo lajes submersas, como é o caso das manchas escuras (Figura 3) na porção ao norte (TAVARES et al. 2010) e ao sul do cabo Búzios, na enseada da Ferradura e na enseada da Praia Brava. Estas estão associadas à presença de fragmentos carbonáticos em concentrações que variam entre 13 e $90 \%$ para estas enseadas.

Os vetores controlados pelos parâmetros estatísticos, calculados pelo modelo GSTA (sobrepostos na Figura 03), indicam as direções modais de transporte 
nas enseadas do cabo Búzios. A sobreposição destes vetores com os valores de diâmetro médio sugere uma relação clara de direção de transporte sobretudo para a porção norte do cabo Búzios (TAVARES et al. 2010) e para a enseada da Ferradura, onde Bulhões e Estrada (2011) encontraram um padrão rotacional anti-horário de circulação relacionado à agitação induzida pelo vento do quadrante nordeste.

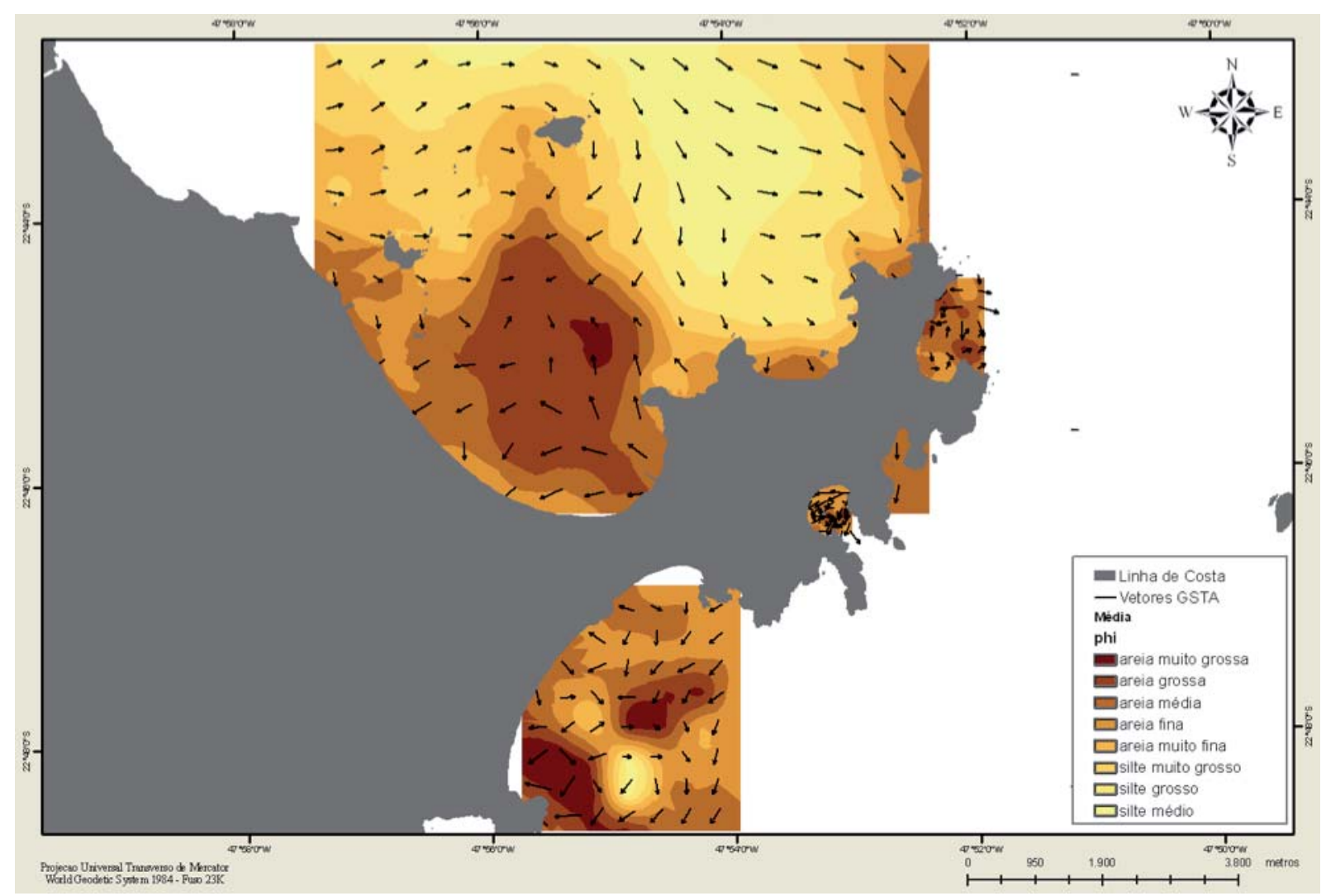

Figura 3 - Diâmetro médio granulométrico e vetores de transporte de sedimentos nas enseadas do cabo Búzios.

Os resultados da sobreposição dos perfis de monitoramento estão sumarizados na Figura 4 e os resultados médios da parametrização morfodinâmica estão descritos na Tabela III. Na borda norte do cabo Buzios, na enseada de Manguinhos, o controle exercido pela orientação da enseada frente às ondas predominantes incidentes do quadrante nordeste determina o aspecto morfodinâmico e as características de propagação das ondas. Ao sudeste desta enseada (Figura 4, perfil K) as ondas tendem a perder energia ao se aproximarem da porção emersa da praia devido ao menor gradiente da antepraia provocando forte dissipação (Tabela III) das ondas incidentes. Há, dessa forma, uma tendência da praia ter características dissipativas de baixa energia nesta extremidade, transitar entre o espectro intermediário na porção central (Figura 4, perfil A) que recebe maior energia e ser refletiva de baixa energia na porção noroeste do arco (Figura 04, perfil J) onde as ondas passam a sofrer menor dissipação e maior refletividade na face da praia (Tabela III). Nestas três posições, o perfil de equilíbrio (Figura 4) encontra-se abaixo dos perfis de monitoramento o que indica área de sedimentação com elevado estoque de sedimentos na zona submarina, o que é justificável também pelas características aplainadas da plataforma continental interna (isolinhas na Figura 1) e do ambiente de sedimentação neotérica de origem fluvial, conforme a Figura 3 .

As posições nas enseadas de João Fernandez (perfil I) e Canto Centro (perfil B) mostram características tipicamente de praias refletivas de baixa energia em que as condições hidrodinâmicas induzidas por ondas são mínimas. Outras características comuns a estas enseadas é o padrão celular de circulação (Tabela III) que revela os efeitos do embaiamento no aspecto morfodinâmico e os baixos valores $(<1,0 \mathrm{~m})$ alcançados para a profundidade de fechamento do perfil ativo. Neste sentido a praia de João Fernandez se asemelharia ao indicado por 

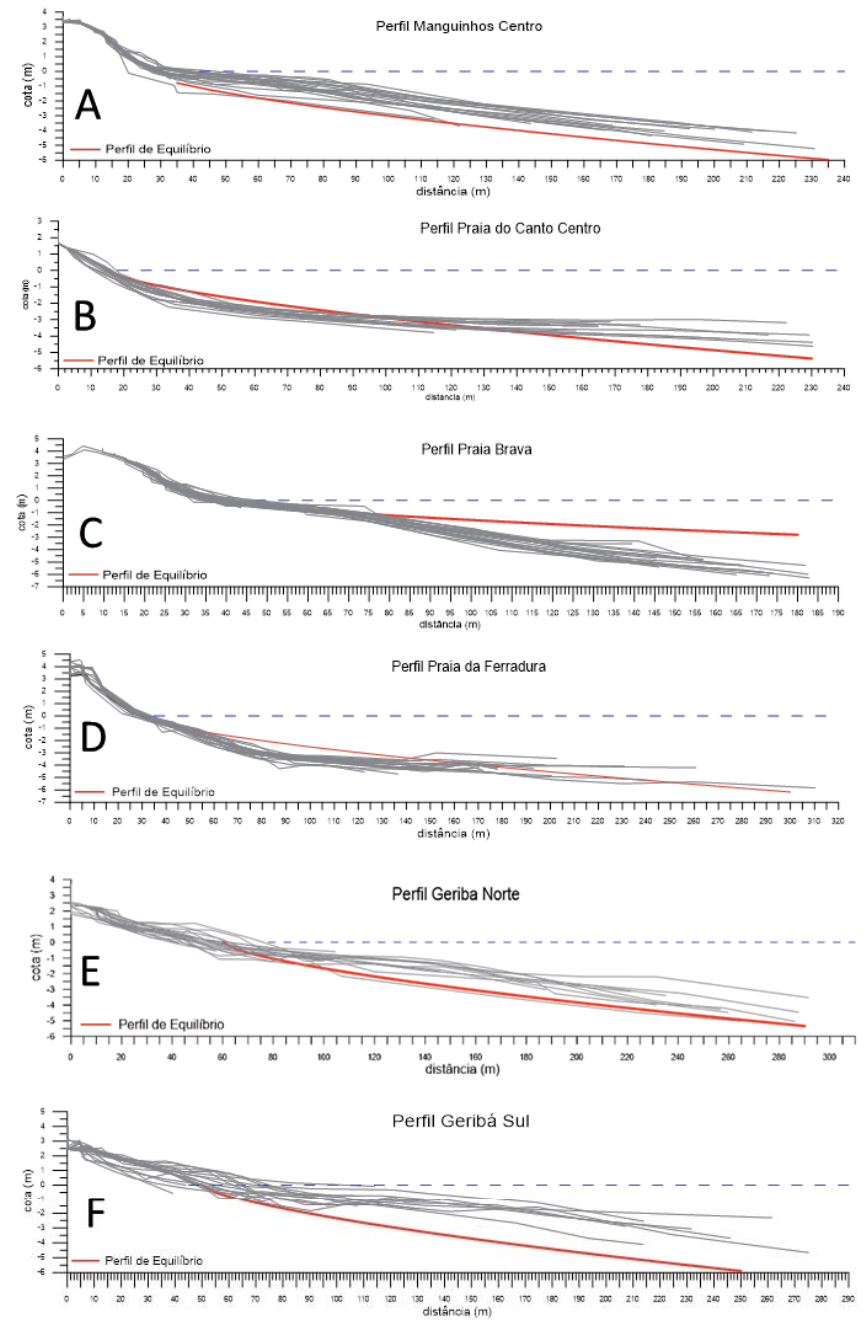

Figura 4 - Sobreposição de perfis de praia das enseadas do cabo Búzios.

Cooper e Pilkey (2004) pela letra c) modificações hidrodinâmicas induzidas pela presença de obstáculos como ilhas, lajes e promontórios rochosos, basicamente em função da presença de lajes submersas (Figura 4, perfil I) ao longo da enseada. Além dessas características, nestas duas enseadas o perfil de equilíbrio encontra-se praticamente ajustado às condições hidrodinâmicas (Figura 4, perfis I e B) e morfossedimentares que compõem o prisma praial.

No setor central do cabo Búzios, as enseadas da Ferradura (perfil D) e praia Brava (perfil C) possuem aspecto diferenciado, pois apesar de apresentarem características intermediárias (Tabela III) de baixa energia, estão eventualmente sujeitas a eventos de alta energia de ondas, conforme presenciado e simulado (Figura 5) durante o levantamento de 9 de abril de 2010 (descrito por BULHÕES et al. 2010 e FERNANDEZ et al. 2011). Nesta condição ocorreu erosão do estoque emerso
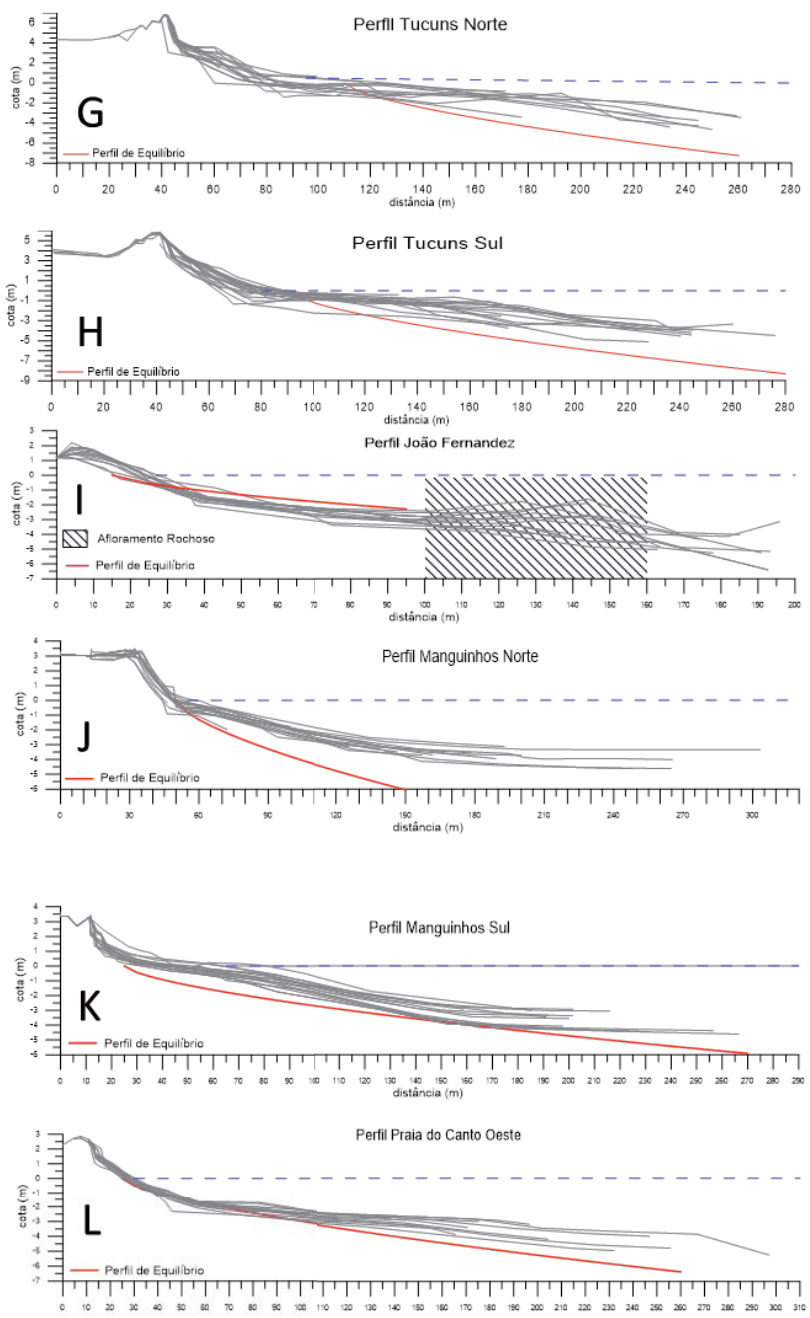

de sedimentos (BULHÕES e FERNANDEZ, 2011) tornando erodidas as feições da praia e do pós-praia, semelhantes ao descrito pelo impacto do tipo "swash regime" segundo a classificação de Sallenger (2000). A enseada da praia Brava apresenta aspecto de perfil permanentemente erodido de acordo com o que Cooper e Pilkey (2004) definem como controle geológico que leva a praia a ter (b) volume deficitário de sedimentos, fato também discutido por Bulhões et al. (2013) que evidenciam na comparação entre os perfis monitorados e o perfil de equilíbrio (figura 4, perfil C). Já a enseada da Ferradura apresentou recuperação plena poucos meses após o evento episódico de tempestade (BULHÕES et al. 2014).

A borda sul do cabo Búzios, na enseada de Geribá-Tucuns, apresenta características completamente distintas das demais. As características transitam entre praias intermediárias (perfis $\mathrm{F}, \mathrm{G}$ e $\mathrm{H}$ ) e dissipativas 
(perfil E) de alta energia. Devido às características de sedimentação mais fina no sistema praia-antepraia em Geribá (perfis E e F) há completa dissipação da energia de ondas (Tabela III) ao longo da zona de surfe, enquanto que na praia de Tucuns (perfis $\mathrm{G}$ e $\mathrm{H}$ ), as ondas do tipo mergulhante sofrem forte dissipação, no entanto, mantendo ainda alguma refletividade na face da praia o que torna maior a variabilidade volumétrica na porção emersa do perfil (Figura 4, perfis $\mathrm{G}$ e $\mathrm{H}$ ).

Durante eventos de tempestade, que para esta porção do litoral podem ser das direções sul, su-sudeste ou su-sudoeste (BULHOES et al. 2014 e OLIVEIRA et al. 2015), há ampla movimentação do estoque de sedimentos tornando a praia estreita e o pós-praia erodido, sobretudo, entre os meses de abril e setembro, conforme indicado por Bulhões et al. (2014) como a temporada de tempestades para o litoral do Rio de Janeiro. Adicionalmente, dentre todos os pontos monitorados, os perfis Tucuns Norte (perfil G) e Geribá Sul (perfil F) apresentaram características de praias de alta energia (BULHÕES et al. 2013), do tipo intermediário (Tabela III), cujo mecanismo predominante de circulação ocorre através de sistemas de correntes longitudinais e de retorno. O típico aspecto de praia intermediária exposta à alta energia de ondas e eventos severos de tempestades, aliado ao elevado estoque de areias promove movimentação significativa no estoque de sedimentos (Figura 8), provavelmente até profundidades entre 12 e 22 metros (Tabela III), tornando essas praias sujeitas a episódicos perfis de tempestade.

A utilização do parâmetro de embaiamento pôde classificar os tipos de circulação preferenciais das enseadas tomando como base os pontos monitorados. As enseadas que apresentaram padrão tipicamente celular foram as da praia Brava (perfil C), praia do Canto (perfis B e L), e João Fernandez (perfil I), sendo este o padrão que atesta os "end effects" (SHORT (1999) e KLEIN (2004)) na característica dinâmica destas praias, coerente também com o indicado por Cooper e Pilkey (2004). A posição monitorada na enseada da Ferradura (perfil D) assim como a posição Geribá Sul (perfil F), apresentaram características do tipo transicional em que os efeitos do embaiamento promovidos pela posição dos promontórios rochosos são menos relevantes para a circulação, porém ainda com alguma influência, sobretudo na modulação do transporte longitudinal. Já a enseada de Manguinhos (perfis A, J e K), a posição Geribá Norte (perfil E) e a enseada de Tucuns (perfis G e H) apresentaram características do tipo normal cuja circulação predominante estaria completamente livre dos efeitos de embaiamento.

Ainda de acordo com o descrito acima, as condições do tipo normal e do tipo celular são nitidamente relacionáveis à extensão da enseada, quanto maior e mais aberta, menores são os efeitos e o inverso também mostra-se verdadeiro. No entanto, a enseada da Ferradura, típica praia de enseada no formato espiral (BULHÕES E ESTRADA, 2011) é pequena e estrangulada entre promontórios rochosos que controlam totalmente a entrada de energia de ondas. Neste caso, atesta-se a localização do perfil na posição central da enseada, posição exposta frontalmente à entrada de ondas (Figura 5) como justificativa para o padrão transicional encontrado.

Simulações de propagação de ondas para águas rasas nas enseadas do cabo Búzios e proximidades, conforme apresentados em estudos de Bulhões e Fernandez (2011) na identificação da alternância entre ondas de tempo bom e de tempestade nas porções norte e sul do cabo Búzios; em Muehe et al. (2011), na identificação de processos erosivos em áreas urbanizadas ao norte do cabo Búzios; e em Bulhões et al. (2016) na identificação dos impactos morfológicos durante a temporada de ondas tempestade ao sul do cabo Búzios; podem revelar, conforme os exemplos das figuras 05 e 07 , a resposta de diferentes enseadas à entrada de ondas.

Estas respostas puderam ser calculadas através da identificação de efeitos de magnificação ou atenuação a partir da comparação das principais direções de entrada e alturas significativas de ondas em águas profundas e depois de propagadas para águas rasas até atingir a zona de arrebentação onde foram consideradas a altura significativa e direção de incidência na zona de arrebentação, os resultados são descritos a seguir:

- Para as ondas de tempestade de su-sudeste (SSE), todos os perfis responderam com atenuação das ondas. É identificado um grupo de perfis protegidos (90\% ou mais de atenuação) destas ondas localizados na borda norte do cabo Búzios, também identificado por Muehe et al. (2011). Os perfis da borda sul apresentam atenuação entre 19\% - Tucuns Norte (perfil G) que é o mais exposto - e 44\% na enseada da Ferradura (perfil D).

- As ondulações provenientes de sudeste (SE) mostram um padrão semelhante ao anterior, porém com magnificação da energia de ondas nos perfis mais ao sul do cabo 
Tabela 3: Resultados dos parâmetros calculados por enseada.

\begin{tabular}{|c|c|c|c|c|c|c|c|c|c|c|c|}
\hline \multirow{3}{*}{ Enseada / Perfll (código) } & \multirow{3}{*}{$\begin{array}{c}\text { Número } \\
\text { de } \\
\text { Levanta } \\
\text { mentos }\end{array}$} & \multicolumn{10}{|c|}{ PARAMETROS } \\
\hline & & \multicolumn{2}{|c|}{ Delta (Muehe, 1998) } & \multicolumn{2}{|c|}{\begin{tabular}{|c|} 
Surf Sealing Parameter \\
(Carrier e \\
Greenspan, 1958; Guza e \\
Bowen, 1975; Guza e \\
Inman, 1975) \\
\end{tabular}} & \multicolumn{2}{|c|}{$\begin{array}{c}\text { Embayment Scale } \\
\text { Parameter (Short, } \\
\text { 1999) }\end{array}$} & \multicolumn{2}{|c|}{$\begin{array}{c}\text { Surf Similarity } \\
\text { Parame ter (Batjes, } \\
\text { 1974) }\end{array}$} & \multicolumn{2}{|c|}{$\begin{array}{l}\text { Profundidade de } \\
\text { Feehamento } \\
\text { (Hallemeier, } \\
\text { 1981; Nichols et } \\
\text { al, 1995) }\end{array}$} \\
\hline & & valor & deseritor & valor & descritor & valor & descritor & valor & descitor & D1 & D1 100 \\
\hline MANGUINHOS NORTE (J) & 15 & 4 & refletivo & 2.25 & $\begin{array}{l}\text { forte refletividade e } \\
\text { redurzida dissipação }\end{array}$ & 43.82 & $\begin{array}{l}\text { normal beach } \\
\text { circulation }\end{array}$ & 1.68 & mergulhante & 1.8 & 3.17 \\
\hline MANGUINHOS CENTRO (A) & 16 & 2.60 & refletivo & 11.38 & forte dissipação & 141.06 & $\begin{array}{c}\text { normal beach } \\
\text { circulation }\end{array}$ & 2.02 & $\begin{array}{l}\text { colapsante ou } \\
\text { ascendente }\end{array}$ & 1.29 & 2.26 \\
\hline MANGUINHOS SUL (K) & 16 & 1.36 & intermediário & 12.19 & forte dissipação & 30.09 & $\begin{array}{c}\text { normal beach } \\
\text { eireulation }\end{array}$ & 0.14 & progressiva & 1.18 & 2.06 \\
\hline CANTO OESTE (L) & 18 & 3.25 & refletivo & 2.24 & forte dissipação & 3.70 & $\begin{array}{c}\text { cellular beach } \\
\text { eirculation }\end{array}$ & 1.39 & mergulhante & 0.51 & 0.9 \\
\hline CANTO CENTRO (B) & 17 & 3.17 & intermediário & 3.11 & forte dissipação & 1.84 & $\begin{array}{l}\text { cellular beach } \\
\text { eireulation }\end{array}$ & 1.1 & mergulhante & 0.38 & 0.67 \\
\hline JOÃO FERNANDEZ (I) & 13 & 4.21 & intermediärio & 2.65 & forte dissipação & 1.00 & $\begin{array}{c}\text { cellular beach } \\
\text { eireulation }\end{array}$ & 2.16 & $\begin{array}{l}\text { eolapsante ou } \\
\text { ascendente }\end{array}$ & 0.49 & 0.86 \\
\hline PRAIA BRAVA (C) & 25 & 1.51 & intermediário & 6.2 & forte dissipação & 0.81 & $\begin{array}{l}\text { cellular beach } \\
\text { circulation }\end{array}$ & 1.09 & mergulhante & 3.3 & 5.7 \\
\hline FERRADURA ( D) & 26 & 3.79 & intermediatio & 2.29 & $\begin{array}{l}\text { forte refletividace e } \\
\text { redurizda dissipação }\end{array}$ & 17.79 & $\begin{array}{l}\text { transitional } \\
\text { circulation }\end{array}$ & 1.71 & mergulhante & 2.46 & 4.3 \\
\hline GERIBA NORTE (E) & 23 & 0.43 & dissipativo & 40.7 & completa dissipaçño & 22.75 & $\begin{array}{l}\text { normal beach } \\
\text { circulation }\end{array}$ & 0.4 & mergulhante & 22.12 & 38.7 \\
\hline GERIBÁ SUL ( F ) & 22 & 0.83 & intermediário & 26.72 & eompleta dissipaçăo & 18.01 & $\begin{array}{l}\text { transitional } \\
\text { circulation }\end{array}$ & 0.59 & mergullhante & 16.75 & 29.31 \\
\hline TUCUNS NORTE ( G ) & 17 & 1.49 & intermediánio & 6.18 & forte dissipação & 23.82 & $\begin{array}{c}\text { normal beach } \\
\text { eireulation }\end{array}$ & 1.29 & mergullhante & 21.58 & 37.76 \\
\hline TUCUNS SUL ( H ) & 23 & 1.92 & intermediário & 4.51 & forte dissipação & 22.63 & $\begin{array}{c}\text { normal beach } \\
\text { eireulation }\end{array}$ & 1.4 & mergulhante & 11.59 & 20.28 \\
\hline
\end{tabular}

Fonte: Laboratório de Geografia Física da Universidade Federal Fluminense.
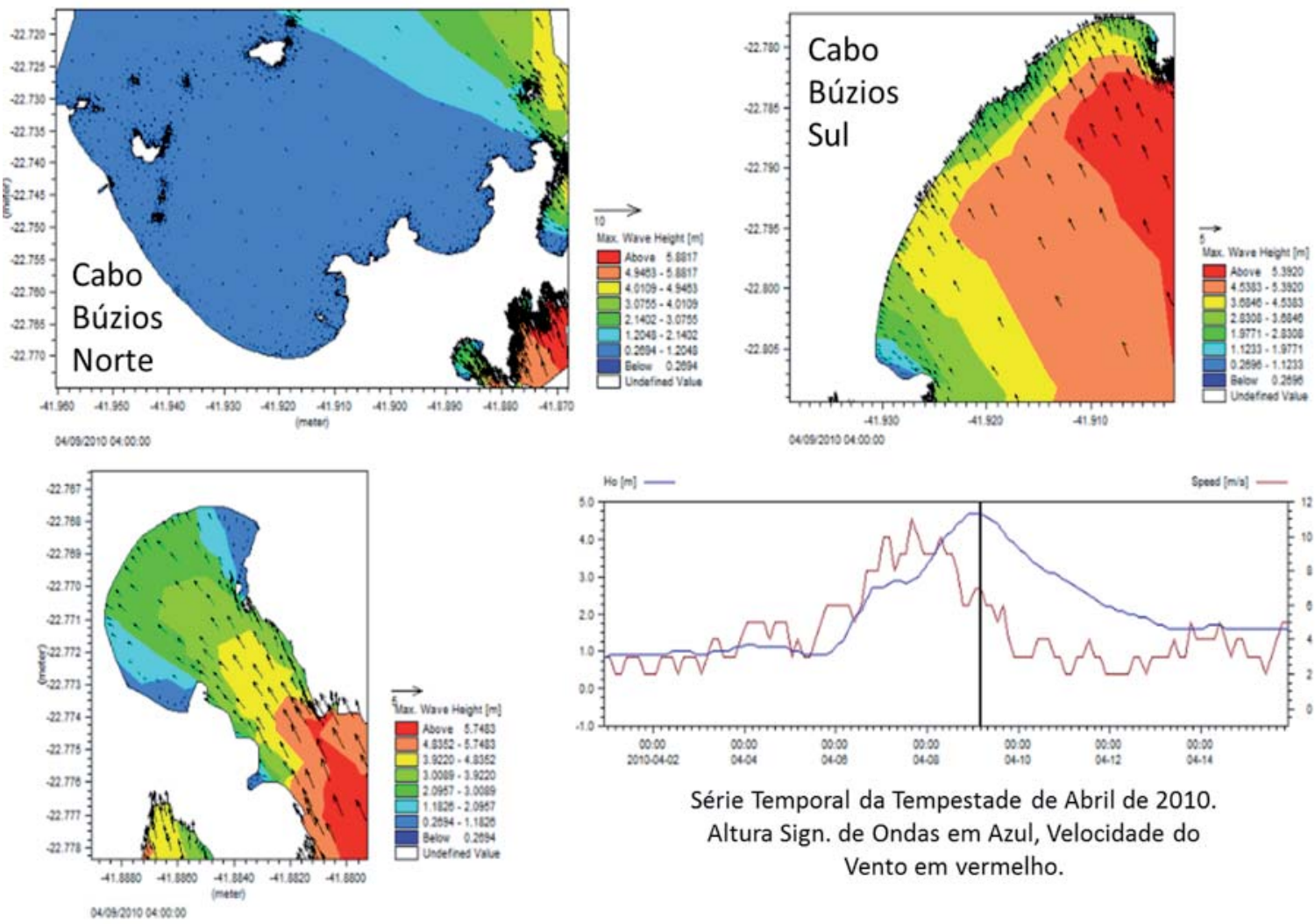

Série Temporal da Tempestade de Abril de 2010.

Altura Sign. de Ondas em Azul, Velocidade do Vento em vermelho.

Cabo Búzios Central - Ferradura

Figura 5 - Propagação de ondas de tempestade e condições no momento ápice da tempestade de abril de 2010 nas porções norte, central e sul do Cabo Búzios. 
Búzios, a saber: Tucuns Sul (perfil H), Tucuns Norte (perfil G) e Geribá Sul (perfil F). O padrão apresentado é resultado da baixa variação no espectro direcional entre a trajetória desde águas profundas até a zona próxima à costa. Os perfis mais protegidos ocorrem na borda norte do cabo Búzios e apresentam alta variação no espectro direcional e isto determina, neste caso, a atenuação das ondas em até $89 \%$.

- O cabo Búzios, de uma forma geral, é protegido frente às ondulações de tempestade de su-sudoeste (SSW) e isto fica evidente observando às variações no espectro direcional que foram entre 45 e $62^{\circ}$. Quanto à atenuação das ondas, esta foi maior nas enseadas da borda norte do cabo Búzios, atingindo valores de até $89 \%$ menores do que as condições ao largo.

- Para ondulações provenientes de sul (S), o perfil Tucuns Norte (perfil G) apresentou ligeira magnificação (3\%) destas ondas e os perfis Geribá Sul (perfil F) e Geribá Norte (perfil E) apresentaram pequena atenuação, aparecendo como os mais expostos a estas ondas de tempestade. Nos demais pontos de monitoramento, a atenuação das ondas segue entre $42 \%$ e $94 \%$, apontando os perfis na borda norte do cabo Búzios como também os mais protegidos.

- As ondas de leste-sudeste (ESE) sofrem magnificação de $12 \%$ no perfil Tucuns Norte (perfil G) e pequena atenuação no perfil Geribá Sul (perfil F). Ainda para a borda sul do cabo Búzios, o perfil Geribá Norte (perfil E) aparece como mais protegido do que o perfil Tucuns Sul (perfil H) que sofreu pequena atenuação. Já na borda norte, há uma heterogeneidade ainda não vista em termos de proteção relativa. Os perfis da praia Brava (perfil C), Ferradura (perfil D), João Fernandes (perfil I) e Manguinhos Centro (perfil A) apresentaram atenuação entre 20 e $30 \%$, mais expostos, portanto, do que os outros perfis próximos (perfis $\mathrm{D}, \mathrm{L}, \mathrm{J}$ e $\mathrm{K}$ ) que foram influenciados por uma maior proteção, seja pela orientação, seja pela presença de ilhas e promontórios rochosos.

- As condições não muito recorrentes de ondas de leste (L), quando propagadas para a costa, permitem observar que novamente os perfis de Tucuns Norte (perfil G) e Tucuns Sul (perfil H) são os mais afetados e respondem com magnificação claramente significativa das ondas ( $37 \%$ e $46 \%$ respectivamente) e mais uma vez a modificação no espectro direcional das ondas é baixa $\left(13^{\circ}\right.$ e $8^{\circ}$ ), o que novamente sugere esta correlação (Figura
6). Todos os outros perfis em monitoramento sofreram atenuação de ondas, ainda sim há uma tendência de que a borda norte seja ainda mais protegida do que a borda sul do cabo Búzios, para estas ondas.

- Para as ondas de norte $(\mathrm{N})$, mostra-se um padrão de atenuação bastante significativo para todas as enseadas e pontos de monitoramento. Estes valores ocorrem acima de $70 \%$.

- Foi observado que as condições de ondas de nordeste (NE), a respeito das condições de ondas de leste (L), também não são de fato as mais recorrentes. Apesar dos ventos regionais soprarem majoritariamente destas direções (PINHO, 2003), a resultante em termos de direção das vagas não é idêntica, ou seja, ventos de nordeste (NE) e leste (L) normalmente geram ondas de nor- nordeste (NNE) ou de leste-nordeste (ENE).

- A condição de ondas de nor-nordeste (NNE) apresenta os perfis da Praia Brava (perfil C) e Manguinhos Sul (perfil K) como mais expostos, com resultantes de magnificação respectivamente de $16 \%$ e $0,6 \%$. Em seguida os perfis de João Fernandez (perfil I), Canto Centro (perfil B) e Manguinhos Norte (perfil J) apresentaram ligeira atenuação (até 3\%). A borda norte do cabo Búzios é mais exposta a estas condições de ondas do que os perfis da borda sul, que apresentaram uma atenuação entre 36\% (perfil H - Tucuns Sul) e 69\% (perfil E - Geribá Norte).

Em uma análise geral não aparece uma relação clara entre atenuação de ondas e a variação direcional que elas sofrem ao se propagar desde águas profundas até penetrar em uma enseada. O gráfico da Figura 6 mostra esta relação e, no entanto, se evidencia que quando ocorre magnificação das ondas dentro das enseadas a variação direcional destas ao largo quando comparadas com águas rasas é pequena.

Sob condições de vento moderado a forte de nordeste (Figura 7), ficou claro que a porção norte do cabo Búzios aparece como mais exposta à turbulência gerada por vagas. Alguns dados (ex. evento dezembro 2006 - Figura 7) para esta borda norte indicam que as praias do Canto (perfis B e L) e João Fernandes (perfil I) aparecem recebendo maior turbulência. Nestes casos a disposição das curvas batimétricas nesta extremidade leste da borda norte do cabo Búzios favorece a concentração de energia de ondas, ilustrando o efeito de convergência de ortogonais para áreas com esta configuração.

Ainda de acordo com o exposto, o efeito oposto aparece na porção central da enseada de Manguinhos, 


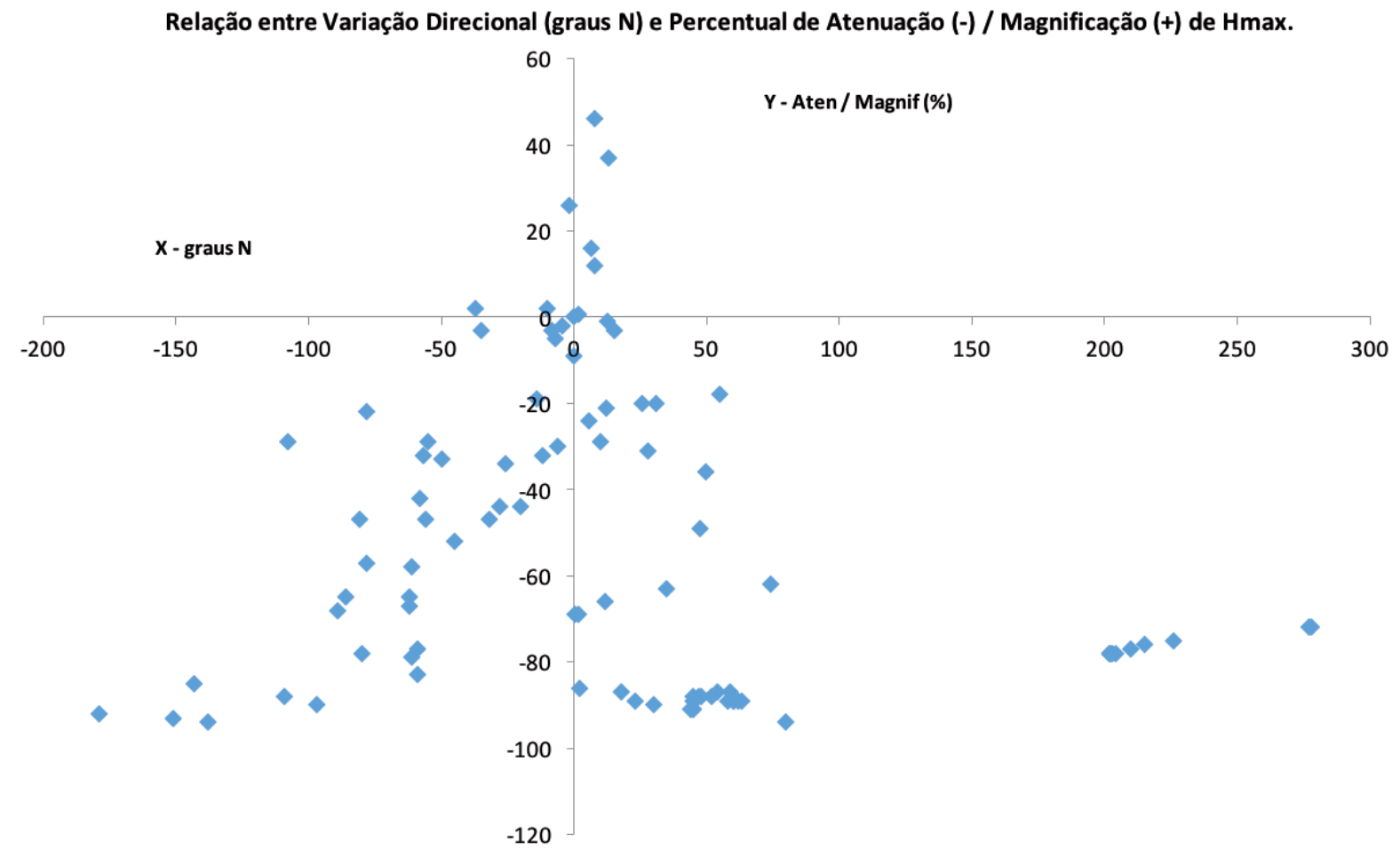

Figura 6 - Relação entre variação direcional e percentual de atenuação/magnificação das ondas incidentes.

onde a disposição mais distal das linhas batimétricas, $o$ relevo mais plano e suave da antepraia e da plataforma continental interna favorecem o efeito de embaiamento, onde há divergência das ortogonais indicando uma maior atenuação da energia de ondas direcionadas para a costa e dissipação destas ao longo da zona de surfe (Tabela III).

As variações na direção das ondas e dos ventos, neste trabalho utilizadas em intervalos de $22,5^{\circ}$ em $22,5^{\circ}$, são diagnósticas de alterações na exposição relativa dos pontos de monitoramento, fazendo com que uma alteração simples neste padrão faça que determinada porção da linha de costa receba maior ou menor energia de ondas que no momento anterior.

Neste sentido, para praias de enseada, os resultados de magnificação ou atenuação de ondas são dependentes das características de águas rasas, diferente do do concluído por Oliveira et al. (2015) que utilizam valores do modelo de águas profundas, sem considerar estimativas de suas alterações para águas rasas, para detectar mudanças morfológicas no perfil da praia de Lagamar, cerca de $70 \mathrm{~km}$ ao norte do cabo Búzios.

$\mathrm{Na}$ borda norte do cabo Búzios, onde o padrão de ventos de nordeste induz maior energia nos perfis da Praia do Canto (Figura 07, linhas verde e magenta) e João Fernandez (Figura 07, linha amarela), ao passo que a entrada de ventos de nor-nordeste induz maior energia à porção central da praia de Manguinhos (Figura 07, linha azul). Outros exemplos foram testados por Bulhões (2011) para ventos e ondas de outras direções e as modificações induzidas também ficaram claras. Mesmo em uma perspectiva de diminuição da velocidade dos ventos, uma ligeira modificação direcional pode induzir a um aumento na altura significativa de ondas em determinada porção da linha de costa em comparação com outra.

A praia de Tucuns (sobretudo em sua porção central e norte) é a enseada que recebe as maiores ondulações e ainda é a porção do litoral mais exposta às ondas que se aproximam tanto do quadrante sul quanto do quadrante leste-sudeste. Estas condições somadas ao elevado estoque de sedimentos (Figura 8) fazem com que esta praia compute as maiores alterações morfológicas na área do cabo Búzios. Esta relação entre as maiores ondas e o maior volume de sedimentos disponíveis como determinantes para as mais elevadas taxas de alteração morfológica foi previamente observada por Daly et al. (2011) para praias de enseada. 


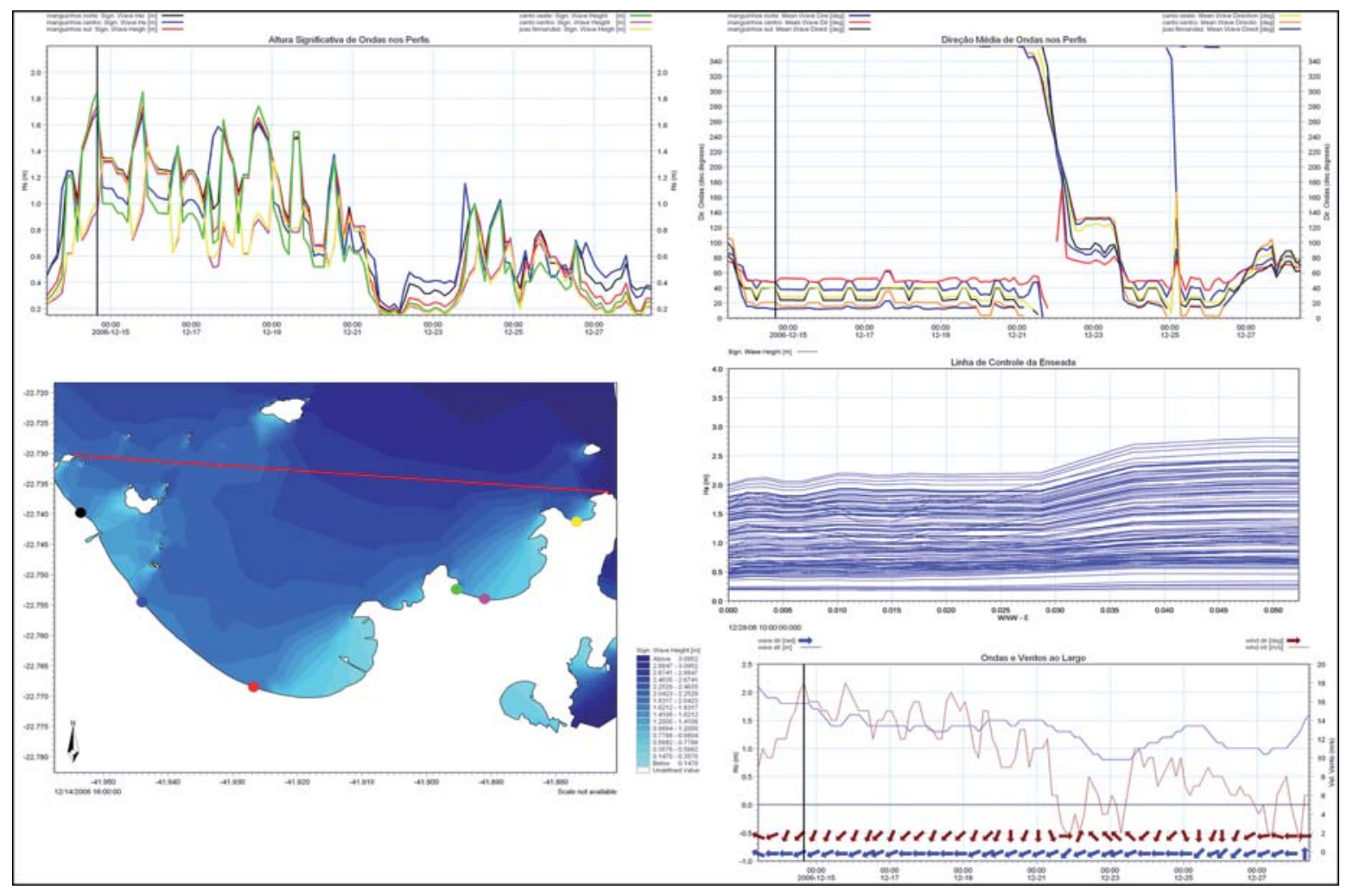

Figura 7 - Simulação do evento de dezembro de 2006, com ondas e ventos do quadrante norte-leste.

$\mathrm{Na}$ análise da variabilidade do volume de sedimentos ao longo do monitoramento dos perfis de praia destaca-se o perfil Tucuns Sul $(\mathrm{H})$ que apresentou a maior variabilidade volumétrica acumulando perda de $38 \mathrm{~m}^{3} / \mathrm{m}$ entre janeiro e novembro de 2008. Bulhões et al. 2014 atribuíram isto à ocorrência de 10 tempestades neste intervalo de tempo.

Existe uma discussão em torno da seleção das condições de onda para projetar o formato de equilíbrio das enseadas e pode-se citar o trabalho de Daly et al. (2014) que indicaram que as mudanças morfológicas causadas por eventos extremos são balanceadas por eventos de calmaria de longa duração e portanto, os autores mostraram que, para a enseada de Milagro Beach na Espanha, as condições mais persistentes são então as que explicam o formato modal das enseadas. No entanto, neste artigo, como também em Bulhões et al. (2014 e 2016), concorda-se com Carter (1998), que indicou as ondas de tempestade como as maiores responsáveis por induzir modificações morfológicas em praias de enseada e com Ferreira (2005) que considera que eventos únicos de extrema magnitude produzem erosão severa nas praias, porém tempestades sucessivas podem induzir a consequências que extrapolam eventos de maior magnitude.

Neste sentido, a tempestade mais forte neste intervalo entre 2003 e 2013 ocorreu em abril de 2010 e os impactos morfológicos decorrentes desta tempestade foram apresentados por Bulhões et al. (2010) e Fernandez et al. (2011) que, no entanto, não apresentaram resultados de variação volumétrica. Estes impactos significaram perda volumétrica percentual na borda sul do cabo Búzios, especificamente nas posições Geribá Norte (perfil E) de 73\%, Geribá Sul (perfil F) de 72\%; Tucuns Sul (perfil H) de 22\%, Tucuns Norte (perfil G) de $11 \%$ e Ferradura (perfil D) de $33 \%$, quando comparados ao volume antecedente.

O efeito inverso, ou seja, de acumulação, ocorre notadamente nos meses em que as tempestades são escassas, sobretudo entre dezembro e março (Tabela II). Ao se observar o período entre outubro de 2009 e fevereiro de 2010, o volume acumulado nos perfis de Geribá Norte (E) foi de $19,5 \mathrm{~m}^{3} / \mathrm{m}$ (ou 44,3\% do volume anterior) e no de Tucuns Sul $(\mathrm{H})$ foi de $54 \mathrm{~m}^{3} / \mathrm{m}(127 \%$ comparado ao volume anterior), algo bastante significativo para a recuperação destes perfis após a temporada de tempestades. 


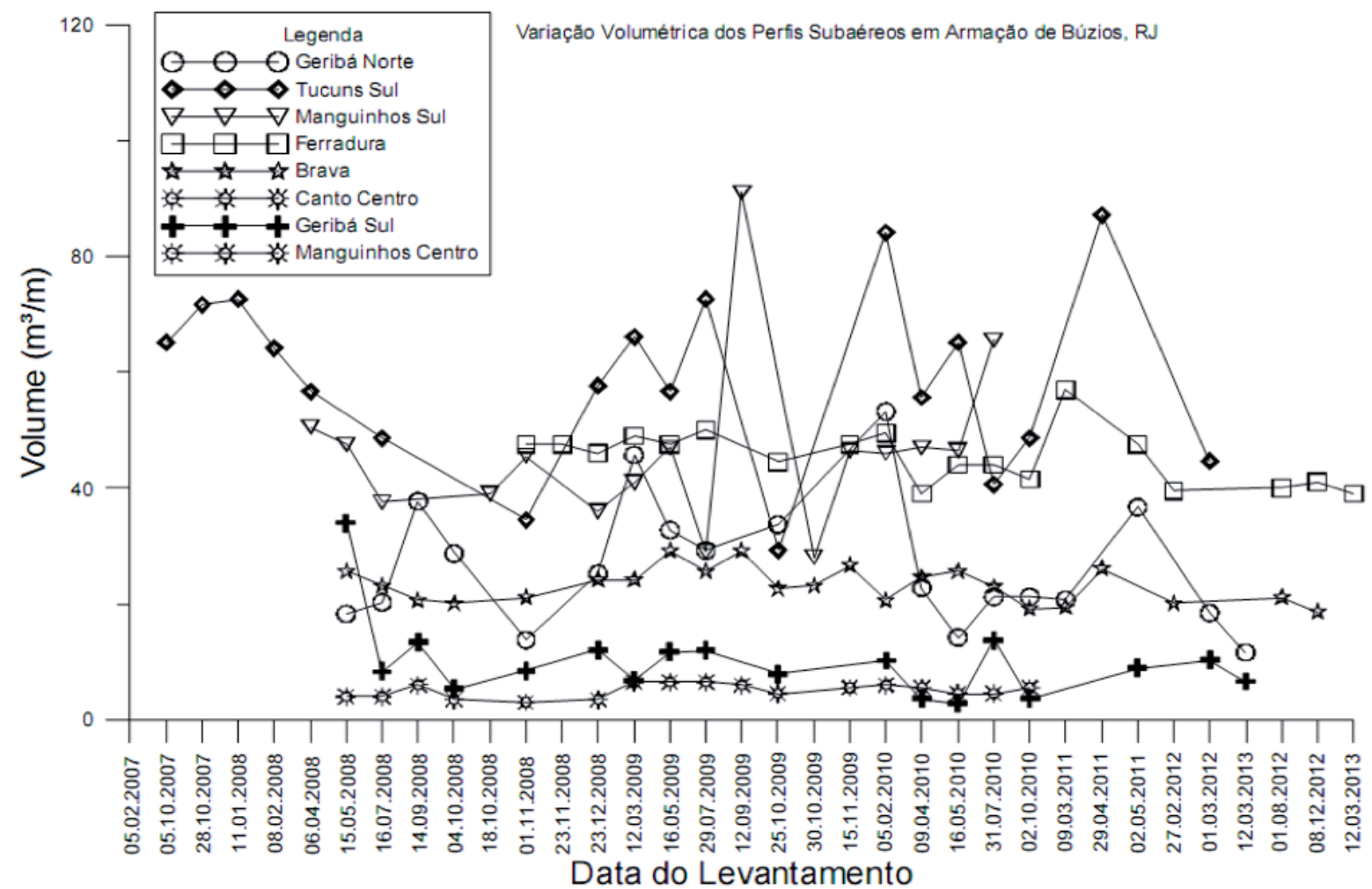

Figura 8 - Variabilidade volumétrica na porção emersa dos perfis de praia monitorados. Extraído de Bulhões et al., (2014).

\section{Conclusões}

Ao revelar a variabilidade do agente deposicional nas enseadas, o parâmetro média granulométrica pôde inicialmente sustentar a hipótese de multimodalidade hidrodinâmica ao qual as enseadas estariam submetidas, estas condições atestam áreas de deposição e áreas de não deposição preferencial em função basicamente da exposição da enseada à entrada de ondas predominantes. A ausência de amostras bem selecionadas nas enseadas do cabo Búzios também atesta estes efeitos em função das misturas de populações, o que é justificado pela presença dos depósitos palimpsestos que recobrem amplas áreas nas enseadas e da deposição carbonática cujas partículas apresentam ampla participação (entre 13 e 90\%) nas amostras. Em direção à praia ocorrem os menores teores diminuindo consequentemente o desvio padrão das amostras.

Três tipos de depósitos são claramente identificáveis. O primeiro é formado predominantemente por siltes e aparece na plataforma continental interna, tem origem fluvial e recente (neotérico), resultado da sedimentação fluvial com origem ao norte do cabo Búzios. O segundo depósito é composto por areias predominantemente médias e finas, na antepraia, resultante do retrabalhamento da porção submarina da barreira arenosa (palimpsesto). Alguns elementos morfológicos do entorno indicam que a fonte desses sedimentos seria o residual da erosão de falésias sedimentares relacionadas ao Grupo Barreiras quando de uma posição mais elevada do nível do mar. O terceiro tipo de depósito é cascalhoso e ocorre localizado nas proximidades de costões rochosos, depósitos de tálus, ilhas e lajes submersas. Este aparece com elevadas concentrações de biodetritos $(>70 \%)$ e é resultado da abrasão local promovida por ondas.

As condições de ondas identificadas para o cabo Búzios são: (a) tempo bom com ventos soprando entre NNE (nor-nordeste) e ESE (leste-sudeste); (b) tempo bom com marulhos de sul ou de sudeste; (c) tempestade com ondas que variam entre su-sudeste $\left(157^{\circ}\right)$ até sudoeste $\left(225^{\circ}\right)$.

As características morfodinâmicas dos perfis monitorados reúnem os atributos morfológicos e sedimentológicos e estes são controlados basicamente pelo efeito das ondas e pela exposição relativa à estas. De uma maneira geral, os 12 perfis monitorados estão classificados entre refletivos, intermediários e dissipativos e ocorrem em condições de baixa ou alta energia, e podem 
ser: (a) refletivos de baixa energia: Manguinhos Norte (J), Canto Centro (B) e João Fernandez (I); (b) intermediários de baixa energia, sujeitos a eventos episódicos de tempestade: Manguinhos Centro (A), Canto Oeste (L), Brava (C) e Ferradura (D); (c) dissipativo de baixa energia: Manguinhos Sul (K); e (d) intermediários de alta energia, Geribá Norte (E) e Sul (F) e Tucuns Norte (G) e Sul (H).

Os limites ativos sobre a influência das ondas dentro das enseadas do cabo Búzios puderam ser determinados em torno da profundidade entre 1 e $6 \mathrm{~m}$ em todas as áreas consideradas de baixa energia no cabo Búzios e, nas áreas sujeitas à alta energia de ondas, este limite pode ser transferido para profundidades superiores a $20 \mathrm{~m}$.

As respostas destes ambientes quanto a um possível aumento na magnitude das ondas de tempestade seriam o desaparecimento sazonal dos ambientes intermediários de baixa energia e um recuo erosivo dos ambientes intermediários de alta energia em função direta do reduzido estoque de sedimentos. Quanto aos ambientes refletivos de baixa energia estes responderiam através de ajuste erosivo em uma condição de aumento do nível médio do mar ou mesmo desapareceriam, se as condições energéticas de ondas assumissem outro espectro direcional de incidência que favorecesse a exposição.

Por fim, atesta-se que as enseadas funcionam como um filtro à entrada das ondulações. Na maior parte das condições este filtro atua atenuando as ondas e reduzindo os efeitos morfológicos nas praias. A característica morfológica em planta e em perfil pode indicar áreas com maior estoque de sedimentos que responderiam diferentemente face a um evento erosivo de ondas de tempestade. Esta resposta seria em função de uma recuperação mais rápida como na Ferradura (perfil D) e em Tucuns (perfis G e H) ou mais lenta como em Geribá (perfis E e F) em relação à condição anterior, ou mesmo pela manutenção de uma característica permanentemente erodida como na praia Brava (perfil C).

\section{Agradecimentos}

O primeiro autor agradece à CAPES pela concessão de bolsa de doutorado entre 2008 e 2011 e aos inúmeros colaboradores do Laboratório de Geografia Marinha da UFRJ e do Laboratório de Geografia Física da UFF. O segundo autor agradece à FAPERJ pela bolsa Jovem Cientista do Nosso Estado (2009-2012) e ao CNPq (Edital Universal 2010-2012) pelo auxílio financeiro para aquisição de dados em campo. Ambos agradecem às contribuições dos revisores.

\section{Referências Bibliográficas}

AMADOR, E.S. Traços Gerais da Evolução Quaternária da Bacia do Rio São João - RJ. Anais do XXX Congresso Brasileiro de Geologia (1), p. 532-556, 1980.

BATJES, J.A. Surf Similarity. Proceedings of the $14^{\text {th }}$ International Conference on Coastal Engineering, p. 466480, 1974.

BRUUN, P. Coastal Erosion and the Development of Beach Profiles. U.S. Army Beach Erosion Board, Technical Memorandum, 44, 1954.

BUlhÕES, E. Exposição de Praias, Clima de Ondas e Processos Físicos em Praias de Enseada : Exemplos e Aplicações em Armação dos Búzios, Rio de Janeiro, Brasil. (Tese de Doutorado). Instituto de Geociências. Universidade Federal Fluminense. Niterói, 230p. 2011.

BULHÕES, E; ESTRADA, A.F.D. Distribuição e Transporte de Sedimentos Costeiros em Ambiente de Baixa Energia. Enseada da Ferradura, Armação dos Búzios, Rio de Janeiro, Brasil. Revista Gravel, Vol. 9 (1), p. 41-56, 2011.

BULHÕES, E.; FERNANDEZ, G.B. Analysis of Shallow Water Wave Propagation and Coastal Response in Embayed Beaches. Case Study in Cape Buzios, Rio de Janeiro, Brazil. Journal of Coastal Research, SI 64, p. 2022-2026, 2011.

BULHÕES, E.; FERNANDEZ, G.B., ROCHA, T. B. 2010. Efeitos morfológicos nas barreiras costeiras do litoral centronorte do estado do Rio de Janeiro: resultados do evento de tempestade de abril de 2010. Revista de Geografia (Recife), Vol. 27 (2), p. 15-29. 2010

BULHÕES, E.; FERNANDEZ, G.B.; ROCHA, T.B. Morphodynamics of Embayed Beaches. Case Study in Cape Buzios, Rio de Janeiro, Brazil. Journal of Coastal Research, SI 65, p. 1739-1744. 2013.

BULHÕES, E.; FERNANDEZ, G.B.; OLIVEIRA FILHO, S.R.; PEREIRA, T.G.; ROCHA, T.B. Impactos Costeiros Induzidos por Ondas de Tempestade entre o Cabo Frio e o Cabo Búzios, Rio de Janeiro, Brasil. Quaternary and Environmental Geosciences, Vol. 5(2), p. 155-165, 2014.

BULHÕES, E.; FERNANDEZ, G.B.; OLIVEIRA FILHO, S.R.; PEREIRA, T.G.; ROCHA, T.B. Coastal Impacts Induced 
by Storm Waves between Cape Frio aand Cape Buzios, Rio de Janeiro, Brazil. Journal of Coastal Research, SI 75, p. 1047$1051,2016$.

CARRIER, G. F. ; GREENSPAN, H.P., Water Waves of Finite Amplitude on a Sloping Beach. Journal of Fluid Mechanics, Vol. 4, p. 97-109, 1958.

CARTER, R.W.G. Coastal Environments: An Introduction to the Physical, Ecological, and Cultural Systems of Coastlines. Academic Press, London. 1988. 617p.

COOPER, J.A.G.; PILKEY, O.H. Sea Level Rise and Shoreline Retreat : Time to Abandon the Bruun Rule. Global and Planetary Change, Vol. 43, p. 157-171, 2004.

DALY, C.; BRYAN, K.R.; GONZALEZ, M.R.; KLEIN, A.H.F.; WINTER, C. Effect of Selection and Sequencing of Representative Wave Conditions on Process-Based Preditcions of Equilibrium Embayed Beach Morphology. Ocean Dynamics, Vol. 64, p. 863-877, 2014.

DALY, C.J.; BRYAN, K.R.; ROELVINK, J.A.; KLEIN, A.H.F.; HEBBLEN, D.; WINTER, C. Morphodynamics of Embayed Beaches: The Effect of Wave Conditions. Journal of Coastal Research, SI 64, p. 1003-1007, 2011.

DAVIES, J.L. Wave Refraction and the Evolution of Shoreline Curves. Geographical Studies, Vol. 5, p.1-14, 1958.

DAVIES, J.L. Geographical Variation in Coastal Development. Oliver \& Boyd. Edinburgh. 1972, 204 p.

DAVIS JR, R.A. Coastal Sedimentary Environments. Springer Verlag. New York, 1985, 716 p.

DEAN, R.G. Equilibrium Beach Profiles: US Atlantic and Gulf Coasts. Ocean Engineering Technical Report. Newarc, n.12, p. 1-45, January, 1977.

FERNANDEZ, G.B. Caracterização Morfodinâmica do Prisma Praial sob Influência de Sedimentos Fluviais, no Embaiamento Rio das Ostras - Cabo Búzios, RJ. (Dissertação de Mestrado) Instituto de Geociências. Programa de Pós Graduação em Geografia. Universidade Federal do Rio de Janeiro. Rio de Janeiro (RJ). 1998.

FERNANDEZ, G.B. ; BULHÕES, E. ; ROCHA, T.B. Impacts of Severe Storm Ocurred in April 2010 along Rio de Janeiro Coast, Brazil. Journal of Coastal Research, SI 64, p.1850-1854, 2011. FERNANDEZ, G.B. ; MUEHE, D. Cobertura Sedimentar Recente e Batimetria da Plataforma Continental Interna entre Macaé e o Cabo Búzios, RJ. Anais do VI Simpósio Nacional de Geografia Física Aplicada. Vol. 1, p. 196-203, 1995.
FERREIRA, O. Storm groups versus extreme single storms: predicted erosion and management consequences. Journal of Coastal Research, SI 42, p. 221-227, 2005.

GAO, S. A Fortran Program for Grain-Size Trend Analysis to Define Net Sediment Transport Pathways. Computers \& Geosciences, Vol.22 (4), Short Note. p. 449-452, 1996.

GAO, S.; COLLINS, M. Analysis of Grain Size Trends for Defining Sediment Transport Pathways in Marine Environments. Journal of Coastal Research. Vol. 10 (1), p.70-78, 1994.

GUZA, R.T. ; BOWEN, A.J. The Resonant Instabilities of Long Waves Obliquely Incident on a Beach. Journal of Geophysical Research, Vol. 80, p. 4529-4534, 1975.

GUZA, R.T.; INMAN, D. (1975) Edge Waves and Beach Cusps. Journal of Geophysical Research, Vol. 80, p. 2997-3012, 1975.

HALLEMEIER, R.J. A Profile Zonation for Seasonal Sand Beaches from Wave Climate. Coastal Engineering. Amsterdam, v.4, p.253-277, 1981a.

HALLEMEIER, R.J. Seaward Limit of Significant Sand Transport by Waves: An Annual Zonation for Seasonal Profiles. Coastal Engineering Technical Aid. No. 81 - 2. CERC. US Army Corps of Engineers. 1981b.

HEILBRON, M.; CHRISPIM, S.J.; ALVES, R.P.; SIMÕES, L.S.A. Geologia do Cabo de Búzios (Estado do Rio de Janeiro). Anais da Academia Brasileira de Ciências, Vol. 54 (3): p. 553-562, 1982.

HSU, J.R.C.; EVANS, C. Parabolic Bay Shapes and Applications. Proceedings of the Institute of Civil Engineers. Part 2. 87. p. 557-570, 1989.

INMAN, D.L. Sorting of Sediments in the Light of Fluid Mechanics. Journal of Sedimentary Petrology, Vol. 19 (2), p. 51-60, 1949.

JACKSON, D.W.T.; COOPER, J.A.G.; DEL RIO, L. Geological Control of Beach Morphodynamic State. Marine Geology, Vol. 216, p. 297-314, 2005.

KLEIN. A.H.F. Morphodynamics of Headland Bay Beaches: Examples from the Coast of Santa Catarina State, Brazil. (PhD Thesis). Faculdade de Ciências do Mar e do Ambiente. Universidade do Algarve. Portugal. 2004.

KRUMBEIN, W.C. Shore Processes and Beach Characteristics. Technical Memorandum, 3, Beach Erosion Board, U.S Army Corps of Engineers. 47p. 1944

LEATHERMAN, S.P. Barrier Island Handbook. University of Maryland, College Park. $3^{\text {rd }}$ edition, 152p. 1998. 
LOUREIRO, C.; FERREIRA, Ó.; COOPER, J. A. G. Contrasting morphologic behaviour at embayed beaches in Southern Portugal. Journal of Coastal Research, Vol. 56, p. 83-87, 2009.

MAHIQUES, M. M.; TESSLER, M.G. e FURTADO, V.V. Characterization of Energy Gradient in Enclosed Bays of Ubatuba Region, South-Eastern Brazil. Estuarine, Coastal and Shelf Science. Vol. 47, p. 431-446, 1998.

MARTENS, D., WILliAMS, T., COWELL, P.J. Mega-rip dimensional analysis on the Sydney coast Australia, and implications for beach-state recognition and prediction. Journal of Coastal Research. Vol. 17, p. 34-42, 1999.

MARTIN, L.; SUGUIO, K. Excursion Route Along The Brazilian Coast Between Santos and Campos. In: International Symposium On Global Changes In South America During The Quaternary. São Paulo. 95p. (Special Publication, n. 2). 1989.

MARTINO, E.; MORENO, L; KRAUS, N.C. Engineering Guidance for the Use of Bayed Beach Formulations. In: Proceedings of Coastal Sediments 03. ASCE. 2003.

McMANUS, D. Modern versus Relict Sediment on the Continental Shelf. Geological Society of America Bulletin, Vol. 86, p.1154-1160, 1975.

McNINCH, J.E. Geological Control in the Nearshore: ShoreOblique Sandbars and Shoreline Erosional Hotspots, MidAtlantic Bight, USA. Marine Geology, Vol. 211, p. 121-141, 2004.

MOHRIAK, W.U.; BARROS, A.Z.N.; FUJITA, A. Magmatismo e Tectonismo Cenozóico na Região de Cabo Frio, RJ. Anais do $3^{\circ}$ Congresso Brasileiro de Geologia. Vol. 6, p. 2873-2885, 1990.

MORENO, L.J.; KRAUS, N.C. Equilibrium Shape of Headland Bay Beaches for Engineering Design. In: Proceedings of Coastal Sediments 99. Volume 1. ASCE. New York. p. 860875, 1999.

MUEHE, D. Estado Morfodinâmico Praial no Instante da Observação: uma Alternativa de Identificação. Revista Brasileira de Oceanografia, 46 (2). p. 157-169. 1998a.

MUEHE, D. O Litoral Brasileiro e sua Compartimentação. In: Guerra, A. J. T. \& Cunha, S.B. (org). Geomorfologia do Brasil. Cap. 7. Bertrand Brasil. 1998b.

MUEHE, D.; FERNANDEZ, G.B.; BULHÕES, E; AZEVEDO, I.F. Avaliação da Vulnerabilidade Física da Orla Costeira em Nível Local, Tomando como Exemplo o Arco Praial entre Rio das Ostras e o Cabo Búzios/RJ. Revista Brasileira de
Geomorfologia, Vol.12 (2), p. 45-58, 2011.

NICHOLLS, R.J.; BIRKEMEIER, M.; HALLERMEIER, R.J. Application of the Depth of Closure Concept. Proceedings of 1996 Coastal Engineering. ASCE. p. 3874-3887, 1996.

OLIVEIRA, L.A.K.; SILVEIRA, N.E.P.; LEÃO, R.R. Morfodinâmica Multitemporal em Praia Refletiva no Litoral Centro-Norte do RJ, em Resposta ao Clima de Ondas Regional. Revista Brasileira de Geomorfologia, Vol. 16 (1), p. 20-36, 2015.

PINHO, U.F. Caracterização dos Estados de Mar na Bacia de Campos. Dissertação de Mestrado. COPPE/UFRJ, Rio de Janeiro. 123 p. 2003

RICCOMINI, C. O Rift Continental do Sudeste do Brasil. (Tese de Doutorado), Instituto de Geociências, Universidade de São Paulo. São Paulo, 1989.

SAAVEDRA, L (ver FILHO) Dinâmica Sedimentar na Plataforma Continental Interna entre a Ilha do Cabo Frio e Cabo Búzios. (Dissertação de Mestrado) Instituto de Geociências. Programa de Pós Graduação em Geografia. Universidade Federal do Rio de Janeiro. Rio de Janeiro (RJ). 1994.

SAAVEDRA, L. ; MUEHE, D. Innershelf Morphology and Sediment Distribution in front of Cape Frio - Cape Buzios embayment. JOPS-I Workshop (Brazilian German Victor Hensen Programme Joint Oceanographic Projects, Niteroi, RJ. p.29. 1993.

SALLENGER, A.H. Storm Impact Scale for Barrier Islands. Journal of Coastal Research, vol. 16(3) p. 890-895, 2000.

SCHMITT, R.S. A Orogenia Búzios - Caracterização de um Evento Tectono-Metamórfico no Domínio Tectônico Cabo Frio - Sudeste da Faixa Ribeira. (Tese de Doutorado) Instituto de Geociências, Programa de Pós-Graduação em Geologia. Universidade Federal do Rio de Janeiro. Rio de Janeiro, 2001.

SHORT, A.D. Handbook of Beach and Shoreface Morphodynamics. John Wiley \& Sons Ltd. Baffins Lane, Chinchester. 1999.

SILVESTER, R. Stabilization of Sedimentary Coastlines. Nature. Vol. 188, p. 467-469, 1960.

SILVESTER, R.; HSU, J.C.R. Coastal Stabilization, Innovative Concepts. Prentice Hall. Englewood Cliffs, New Jersey, p. 578, 1997.

TAVARES, A.C.M. ; BUlhões, E. ESTRADA, A.F. Distribuição de Fácies Sedimentares e Tendências de Transporte 
Aspectos Morfodinâmicos em Praias de Enseada: Estudo de Caso em Armação dos Búzios, RJ

de Sedimentos na Enseada de Manguinhos, Armação dos Búzios, RJ. Revista de Geografia (Recife), Vol. 27 (2), p. 81-97, 2010. THIELER, E.R.; BRILL, A.R. ; CLEARY, W.J.; HOBBS, C.H.; GAMMISCH, R.A. Geology or Wrightsville, North Carolina Shoreface: Implications for the Concept of Shoreface profile of Equilibrium. Marine Geology. Vol. 126, p. 271-287, 1995.

WRIGHT, L.D.; SHORT, A.D., Morphodynamic Variability of
Surf Zones and Beaches: a Synthesis. Marine Geology, Vol. 56, p. 93-118, 1984.

YASSO, W.E. Plan Geometry of Headland-Bay Beaches. Marine Geology, Vol. 73, p.702-714, 1965.

ZALAN, P.V.; OLIVEIRA, J.A.B. Origem e Evolução Estrutural do Sistema de Riftes Cenozóicos do Sudeste do Brasil. Boletim de Geociências da Petrobrás. Vol. 13 (2), p.169-300, 2005. 